\title{
Effects of MON 810 on Non Target Organisms: Participatory Critical Evaluation
}

\author{
Z. T. Dabrowski' ${ }^{1}$ Z. Klukowski ${ }^{2}$, and J. Górecka ${ }^{1}$ \\ ${ }^{1}$ Department of Applied Entomology, Warsaw University of Life Sciences-SGGW, Warsaw, Poland \\ ${ }^{2}$ Department of Plant Protection, Wroclaw University of Environmental and Life Sciences, Wroclaw, Poland
}

Eingegangen: 2. Dezember 2008

The results on the effect of MON 810 maize plants on some nontarget arthropod species evaluated under greenhouse conditions and the methodology of the first planned large scale field experiment on monitoring in Poland will be presented for critical comments and advise from the workshop participants. Due to the restrictive regulations on GMO in Poland only laboratory and greenhouse experiments could start in 2004 on following three trophic levels: (a) flour made of transgenic maize MON 810 - Mediterranean flour moth (Anagasta kühniella) and parasitoid Venturia canescens; (b) maize seedlings cereal aphid Rhopalosiphum padi and its parasitoid Aphidius colemani and (c) maize plants - two-spotted spider mite (Tetranychus urticae) and its predator Phytoseiulus persimilis. Because the toxicity of Cry $1 \mathrm{Ab}$ expressed in MON 810 is specific to larvae of Lepidoptera, two following species were chosen as the non-target organisms: (a) MON 810 pollen spread on white head cabbage leaves - caterpillars of large white butterfly (Pieris brassicae) and (b) common cutworm (Turnip moth) (Agrotis segetum), as a serious polyphagous pest, attacking recently heavily seedlings and mature maize plants later in the season.

To access this journal online: http://www.birkhauser.ch/JVL 